\title{
Clinicopathological Features of Patients with the BRCA1 c.5339T>C (p.Leu1780Pro) Variant
}

\author{
Hyung Seok Park, MD, PhD \\ Jai Min Ryu, MD, PhD² \\ Ji Soo Park, MD, PhD 3 \\ Seock-Ah Im, MD, PhD ${ }^{4,5}$ \\ So-Youn Jung, MD, $P h D^{6}$ \\ Eun-Kyu Kim, MD, PhD 7,8 \\ Woo-Chan Park, MD, PhD ${ }^{9}$ \\ Jun Won Min, MD'10 \\ Jeeyeon Lee, MD, $\mathrm{PhD}{ }^{11}$ \\ Ji Young You, MD, $P h D^{12}$ \\ Jeong Eon Lee, MD, PhD² \\ Sung-Won Kim, MD, PhD ${ }^{13}$
}

*A list of author's affiliations appears at the end of the paper.

Correspondence: Sung-Won Kim, MD, PhD Department of Surgery, Breast Care Center, Daerim St. Mary's Hospital, 657 Siheung-daero, Yeongdeungpo-gu, Seoul 07442, Korea Tel: 82-2-829-9000

Fax: 82-2-3410-6982

E-mail: brcakorea@gmail.com

Co-correspondence: Jeong Eon Lee, MD, PhD Division of Breast Surgery, Department of Surgery, Samsung Medical Center, Sungkyunkwan University School of Medicine, 81 Irwon-ro, Gangnam-gu, Seoul 06351, Korea Tel: 82-2-3410-3479

Fax: 82-2-3410-6982

E-mail: paojlus@hanmail.net

Received June 25, 2019

Accepted January 27, 2020

Published Online January 28, 2020

${ }^{*}$ Hyung Seok Park and Jai Min Ryu contributed equally to this work.

\section{Purpose}

Recent studies revealed the BRCA1 c.5339T>C, p.Leu1780Pro variant (L1780P) is highly suggested as a likely pathogenic. The aim of this study was to evaluate clinicopathologic features of L1780P with breast cancer (BC) using multicenter data from Korea to reinforce the evidence as a pathogenic mutation and to compare L1780P and other BRCA1/2 mutations using Korean Hereditary Breast Cancer (KOHBRA) study data.

\section{Materials and Methods}

The data of $54 \mathrm{BC}$ patients with L1780P variant from 10 institutions were collected and the clinicopathologic characteristics of the patients were reviewed. The hereditary breast and/or ovarian cancer-related characteristics of the L1780P variant were compared to those of BC patients in the KOHBRA study.

\section{Results}

The median age of all patients was 38 years, and $75.9 \%$ of cases showed triple-negative breast cancer. Comparison of cases with L1780P to carriers from the KOHBRA study revealed that the L1780P patients group was more likely to have family history (FHx) of ovarian cancer (OC) ( $24.1 \%$ vs. $19.6 \%$ vs. $11.2 \%, p<0.001$ and $p=0.001)$ and a personal history of $\mathrm{OC}(16.7 \%$ vs. $2.9 \%$ vs. $1.3 \%, p=0.003$ and $p=0.001)$ without significant difference in $\mathrm{FHx}$ of $\mathrm{BC}$ and bilateral $\mathrm{BC}$. The cumulative risk of contralateral $\mathrm{BC}$ at 10 years after diagnosis was $31.9 \%$, while the cumulative risk of OC at 50 years of age was $20.0 \%$. Patients with L1780P showed similar features with BRCA1 carriers and showed higher penetrance of OC than patients with other BRCA1 mutations.

\section{Conclusion}

L1780P should be considered as a pathogenic mutation. Risk-reducing salpingo-oophorectomy is highly recommended for women with L1780P.

\section{Key words}

Breast neoplasms, BRCA1, c.5339T>C, p.Leu1780Pro, Survival, Prognosis 


\section{Introduction}

$B R C A 1$ is a tumor suppressor gene, and its mutation is significantly associated with hereditary breast cancer (BC) and ovarian cancer (OC) (HBOC) syndrome [1,2]. A variant of unknown significance (VUS) is a genetic variant that has been identified by genetic testing but of which the functional significance is not fully understood at this time [3]. Although considerable effort has been put into reclassification of VUSs, still, standardized guidelines have yet to be established.

The BRCA1 c.5339T>C, p.Leu1780Pro (L1780P) variant was considered a VUS until previous studies revealed that it is associated with HBOC syndrome [4-6]. Three studies from Korea suggested that this variant showed highly suspected features of a pathogenic BRCA1 mutation. However, all the previous studies included fewer than 20 patients; thus, there is a degree of uncertainty about the pathogenicity of the L1780P mutation that has remained. Furthermore, interestingly, reports of this variant are confined to the Korean population, and this variant has not been identified in Western countries [7-10].

We evaluated the clinicopathologic features of the L1780P variant in patients with $\mathrm{BC}$ using retrospective multicenter data from Korea to verify L1780P as a pathogenic BRCA1 mutation. We also compared the characteristics related to HBOC syndrome to identify HBOC-related characteristics between the L1780P variant and other locations of BRCA1/2 mutations.

\section{Materials and Methods}

\section{Patients}

Twelve institutions initially agreed to participate in this study. Ten of them subsequently provided data from patients with L1780P (S1A and S1B Fig.). Two institutions agreed to participate in the study but could not identify patients with the L1780P variant. One institute did not provide information on the number of BRCA1/2 mutations. There was insufficient clinical information for five patients with L1780P. Finally, a total of 64 patients with L1780P and BC and/ or OC from the 10 institutions was enrolled in this retrospective study (Fig. 1).

The clinicopathologic data and information were reviewed. The clinicopathologic data included parity, marital status, age at diagnosis, family history (FHx), and personal history (PHx) of BC and/or OC, bilaterality of BC, pathologic stage according to the seventh American Joint Committee on Can-

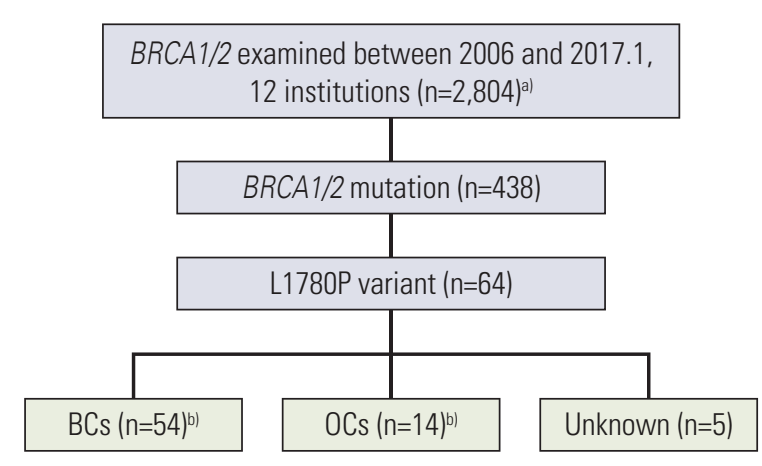

Fig. 1. Schematic diagram of patient enrollment. BC, breast cancer; OC, ovarian cancer. ${ }^{\text {a) }}$ Two institutions have no data of L1780P variant, ${ }^{b}$ Nine patients had breast and ovarian cancer.

cer classification, estrogen receptor (ER), and progesterone receptor (PR) status, human epidermal growth factor-2 (HER2) status, nuclear grade, Ki-67 status, type(s) of operation, type(s) of adjuvant treatment, risk-reducing procedures, sampling date, genetic testing method(s), and tumor subtype(s). We compared the HBOC-related characteristics in the patients with the L1780P variant to those of BC patients from the Korean Hereditary Breast Cancer (KOHBRA) study. Detailed information of enrolled patients in the KOHBRA study has been previously described [11]. The clinical outcomes were analyzed considering the following variables: recurrence, metachronous contralateral $\mathrm{BC}$, and mortality. Personal identifiers for all patients were removed prior to analysis.

\section{Diagnostic method}

The BRCA1 L1780P variant was diagnosed using Sanger sequencing (62 patients), next-generation sequencing (one patient), conformation sensitive gel electrophoresis (one patient), and denaturing high-performance liquid chromatography (one patient). Detailed information of the diagnostic methods in the KOHBRA study was described previously [11].

\section{Statistics}

Patient characteristics were compared using independent $\mathrm{t}$ test for continuous variables and chi-square or Fisher exact test for categorical variables. Values are reported as mean \pm standard deviation or median with range. Survival curves were plotted using the Kaplan-Meier method. Recurrencefree survival (RFS) rate was calculated from the date of diagnosis or operation to the date of recurrence. Event-free 
Table 1. Characteristics of breast cancer patients with $B R C A 1$ c.5339T>C (p.Leu1780Pro)

\begin{tabular}{|c|c|}
\hline Variable & No. $(\%)$ \\
\hline Total & 54 \\
\hline \multicolumn{2}{|l|}{ Parity } \\
\hline Yes & $36(66.7)$ \\
\hline No & $16(29.6)$ \\
\hline Unknown & $2(3.7)$ \\
\hline \multicolumn{2}{|l|}{ Marriage } \\
\hline Yes & $40(74.1)$ \\
\hline No & $12(22.2)$ \\
\hline Unknown & $2(3.7)$ \\
\hline \multicolumn{2}{|l|}{ Histologic grade } \\
\hline Low & $1(1.9)$ \\
\hline Intermediate/High & $41(75.9)$ \\
\hline Unknown & $12(22.2)$ \\
\hline \multicolumn{2}{|l|}{ ER status } \\
\hline Negative & $42(77.8)$ \\
\hline Positive & $8(14.8)$ \\
\hline Unknown & $4(7.4)$ \\
\hline \multicolumn{2}{|l|}{ PR status } \\
\hline Negative & $45(83.3)$ \\
\hline Positive & $5(9.3)$ \\
\hline Unknown & $4(7.4)$ \\
\hline \multicolumn{2}{|l|}{ HER2 status } \\
\hline Negative & $49(90.7)$ \\
\hline Overexpression & $2(3.7)$ \\
\hline Equivocal & 0 \\
\hline Unknown & $3(5.6)$ \\
\hline \multicolumn{2}{|l|}{ T categorya) } \\
\hline Tis & $3(5.5)$ \\
\hline $\mathrm{T} 1$ & $27(50.0)$ \\
\hline $\mathrm{T} 2$ & $16(29.6)$ \\
\hline T3 & $3(5.6)$ \\
\hline $\mathrm{T} 4$ & $1(1.9)$ \\
\hline Unknown & $4(7.4)$ \\
\hline \multicolumn{2}{|l|}{$\mathrm{N}$ category ${ }^{\mathrm{a})}$} \\
\hline N0 & $31(57.4)$ \\
\hline $\mathrm{N} 1$ & $16(29.6)$ \\
\hline N2 & $1(1.9)$ \\
\hline N3 & $2(3.7)$ \\
\hline Unknown & $4(7.4)$ \\
\hline \multicolumn{2}{|l|}{ Ki67 (\%) } \\
\hline$>14.0$ & $10(18.5)$ \\
\hline$\leq 14.0$ & $25(46.3)$ \\
\hline Unknown & $19(35.2)$ \\
\hline \multicolumn{2}{|l|}{ Breast operation } \\
\hline BCS & $32(59.3)$ \\
\hline $\mathrm{TM}$ & $22(40.7)$ \\
\hline
\end{tabular}

(Continued)
Table 1. Continued

\begin{tabular}{lc} 
Variable & No. (\%) \\
Axillary operation & \\
SLNB & $25(46.3)$ \\
ALND & $26(48.1)$ \\
Unknown & $3(5.5)$ \\
Anti-estrogen therapy & \\
Yes & $12(22.2)$ \\
\hline No & $39(72.2)$ \\
\hline Unknown & $3(5.5)$ \\
\hline Adjuvant chemotherapy ${ }^{b)}$ & \\
Yes & $37(68.5)$ \\
\hline No & $16(29.6)$ \\
\hline Unknown & $1(1.9)$ \\
Neoadjuvant chemotherapy & \\
\hline Yes & $12(22.2)$ \\
\hline No & $35(64.8)$ \\
\hline Unknown & $7(13.0)$ \\
\hline Adjuvant radiotherapy & \\
\hline Yes & $36(66.7)$ \\
\hline No & $15(27.8)$ \\
\hline Unknown & $3(5.5)$ \\
\hline
\end{tabular}

ER, estrogen receptor; PR, progesterone receptor; HER2, human epidermal growth factor-2; BCS, breast conserving surgery; TM, total mastectomy; SLNB, sentinel lymph node biopsy; ALND, axillary lymph node dissection. ${ }^{\mathrm{a}} \mathrm{Ten}$ patients were staged after neoadjuvant chemotherapy, ${ }^{b}$ Three patients underwent neoadjuvant and adjuvant chemotherapy.

survival (EFS) rate was calculated from the date of diagnosis or operation to the date of any event related to $\mathrm{BC}$ and/or OC. RFS was defined as any recurrence related to BC (e.g., local recurrence, distant metastasis, contralateral $\mathrm{BC}$, and death due to $\mathrm{BC}$ ). EFS was defined as any recurrence related to BC and/ or OC (local recurrence, distant metastasis, contralateral BC, OC, and death by any cause). All tests were two-sided. A p-value of $<0.05$ was considered statistically significant. The SAS ver. 9.4 (SAS Institute Inc., Cary, NC) and R3.2.1 (http:// www.R-project.org; R Foundation for Statistical Computing, Vienna, Austria) software packages were used for statistical analyses.

\section{Ethical statement}

The World Medical Association Declaration of Helsinki on medical research protocols and ethics was adhered to throughout the procedures of this study. The Institutional Review Board (IRB) reviewed and approved this study (IRB number of National Cancer Center: 2017-04021, Kyungpook National 
University Hospital: 2015-05-205, Samsung Medical Center: 2016-09-038, Seoul National University Hospital: 1702-063831, St. Mary's Hospital: KC19REDI0387, Yonsei University Severance Hospital: 4-2016-1116). The need for informed consent was waived because of the low risk posed by this investigation. The authors have declared that no competing interests exist.

\section{Results}

\section{Prevalence}

A schematic diagram of patient selection is shown in Fig. 1. Overall 2,804 BRCA1/2 mutation tests were performed in patients with BC and/or OC. Of those, 438 patients $(15.6 \%)$ had a BRCA1/2 mutation and 64 of 438 patients $(14.6 \%)$ had the L1780P variant. One thousand six hundred sixty-nine BC patients in KOHBRA, 102 BRCA1 (6.1\%), 143 BRCA2 (8.6\%), and two $B R C A 1 / 2(0.1 \%)$ mutations were identified, while 1,442 patients $(86.4 \%)$ did not show BRCA1/2 mutation.

\section{Patient characteristics}

The clinicopathologic and treatment characteristics of the 54 BC patients with the L1780P variant are summarized in Table 1. Only one patient $(1.9 \%)$ showed a low histologic grade while 41 patients $(75.9 \%)$ demonstrated an intermediate to high nuclear grade. More than two-thirds of patients showed ER and PR negativity (ER negativity: 42/54, 77.8\% and PR negativity: 45/54, 83.3\%). HER2 overexpression was present in only two patients $(3.7 \%)$. Triple-negative breast cancer was the most common subtype $(41 / 54,75.9 \%)$.

\section{Clinical features related to $\mathrm{HBOC}$ syndrome in the pati- ent with L1780P compared with patients with $B R C A 1 / 2$ mutation in KOHBRA}

The characteristics related to HBOC syndrome in patients L1780P and those with BRCA1/2 mutation in KOHBRA are shown in Table 2. There was no significant difference in mean age of $\mathrm{BC}$ or age group of $\mathrm{BC}(\leq 40$ and $>40$ year groups) between cases with L1780P and those with BRCA1/2 mutation in KOHBRA (L1780P vs. BRCA1 vs. BRCA2, $\mathrm{p}>$ 0.999 and $\mathrm{p}=0.107, \mathrm{p}=0.652$ and $\mathrm{p}=0.144$, respectively). Patients with L1780P were more likely to have FHx of BC or OC $(48 / 54,88.9 \%)$ than patients with $B R C A 1 / 2$ mutation in $\operatorname{KOHBRA}(75.3 \%, 186 / 241, \mathrm{p}<0.001)$.

Patients with L1780P were more likely to have FHx of OC $(24.1 \%)$ and PHx of OC $(16.7 \%)$ than those with BRCA1/2 mutation in KOHBRA ( $p<0.001$ and $p=0.001, p=0.003$ and $\mathrm{p}=0.001$, respectively). There was no significant difference in FHx of BC, bilateral BC, or number of relatives with $B C$ between L1780P and BRCA1/2 mutation groups, but the L1780P variant group was more likely to have FHx of OC ( $24.1 \%$ vs. $19.6 \%$ vs. $11.2 \%, \mathrm{p}<0.001$ and $\mathrm{p}<0.001)$, and PHx of OC ( $16.7 \%$ vs. $2.9 \%$ vs. $1.3 \%, \mathrm{p}=0.009$ and $\mathrm{p}<0.001)$. In addition, the L1780P variant group had more number of relatives with BC than BRCA1/2 mutation of KOHBRA (all, $\mathrm{p}<$ 0.001). There was no significant difference in the number of relatives with $\mathrm{OC}$ between L1780P BRCA1/2 mutation of $\operatorname{KOHBRA}(\mathrm{p}=0.351$ and $\mathrm{p}=0.166$, respectively). There was no significant difference in the median age of OC onset $(p=0.615$ and $\mathrm{p}=0.800$, respectively).

\section{Clinical outcomes related to HBOC syndrome}

RFS and EFS curves are shown in Fig. 2. The 5- and 10-year RFS rates of patients with L1780P were $78.9 \%$ and $48.3 \%$, respectively (Fig. 2A), and the 5- and 10-year EFS rates of patients with L1780P were $52.4 \%$ and 28.8 (Fig. 2B). Thirteen BC patients demonstrated bilateral breast cancer. The cumulative risk of contralateral $\mathrm{BC}$ at 10 years after diagnosis was $31.9 \%$, while the cumulative risk of OC at 50 years of age was $20.0 \%$ (Fig. 3A and B).

\section{Discussion}

This study clearly demonstrated the clinicopathologic features of patients with L1780P mutation using data collected from 10 institutions in Korea and compared to other locations of BRCA1/2 mutation of KOHBRA. To our knowledge, this study is the largest study of patients with L1780P variants and provides clear evidence that patients with L1780P have similar clinicopathologic features to those of patients with a pathogenic BRCA1 mutation. Patients with the L1780P variant were more likely to have more frequent $\mathrm{FHx}$ and $\mathrm{PHx}$ of OC than patients with other BRCA1/2 mutations in the KOHBRA study.

Some pathogenic variants occur with high frequency because of a "founder effect" in particular racial/ethnic groups. Several founder mutations have been identified in specific populations, including Ashkenazi Jews [12-15]. The three well-known founder mutations in the Ashkenazi Jew population, BRCA1-185delAG, BRCA1-5382insC, and BRCA26174 delT pathogenic variants, account for about $90 \%$ of all $B R C A 1 / 2$ mutations in that population [16]. Interestingly, the L1780P variant showed high frequency only in the Korean population (Table 3). Previous research highlighted 33 pati- 
Table 2. Clinicopathologic features related to HBOC syndrome in breast cancer patients with L1780P and in the KOHBRA study

\begin{tabular}{|c|c|c|c|c|c|c|c|}
\hline & \multirow{2}{*}{ L1780P } & \multicolumn{3}{|c|}{ KOHBRA study } & \multirow{2}{*}{ p-value ${ }^{a)}$} & \multirow{2}{*}{ p-value ${ }^{b)}$} & \multirow{2}{*}{ p-value ${ }^{c}$} \\
\hline & & BRCA1 & $B R C A 2$ & Non-BRCA1/2 & & & \\
\hline Age of BC (yr) & $38.4 \pm 8.0$ & $37.6 \pm 8.4$ & $41.3 \pm 9.9$ & $40.3 \pm 9.3$ & $>0.999$ & 0.107 & 0.272 \\
\hline \multicolumn{8}{|l|}{ Age group (yr) } \\
\hline$\geq 40$ & $36(66.7)$ & $73(71.6)$ & $77(53.8)$ & $871(61.3)$ & $>0.999$ & 0.432 & $>0.999$ \\
\hline$<40$ & $18(33.3)$ & $29(28.4)$ & $66(46.2)$ & $551(38.7)$ & & & \\
\hline No. of relatives with $B C$ & $1.6 \pm 0.7$ & $1.0 \pm 0.9$ & $0.9 \pm 0.9$ & $0.5 \pm 0.7$ & $<0.001$ & $<0.001$ & $<0.001$ \\
\hline \multicolumn{8}{|l|}{ Closet degree of relatives with $\mathrm{BC}$} \\
\hline First-degree & $27(50.0)$ & $45(44.1)$ & $59(41.3)$ & $359(25.2)$ & $>0.999$ & 0.734 & $<0.001$ \\
\hline Second-degree & $17(31.5)$ & 0 & $1(0.7)$ & $2(0.1)$ & $<0.001$ & $<0.001$ & $<0.001$ \\
\hline \multicolumn{8}{|l|}{ No. of relatives with $B C$} \\
\hline 0 & $20(37.0)$ & $35(34.3)$ & $45(31.5)$ & $809(56.9)$ & $>0.999$ & 0.321 & $<0.001$ \\
\hline 1 & $18(33.3)$ & $41(40.2)$ & 74 (51.7) & $525(36.9)$ & & & \\
\hline 2 & $11(20.4)$ & 19 (18.6) & $18(12.6)$ & $74(5.2)$ & & & \\
\hline$\geq 3$ & $4(7.4)$ & $7(6.9)$ & $6(4.2)$ & $14(1.0)$ & & & \\
\hline Unknown & $1(1.9)$ & 0 & 0 & 0 & & & \\
\hline \multicolumn{8}{|l|}{$\begin{array}{l}\text { Bilateral BC } \\
\text { (including metachronous BC) }\end{array}$} \\
\hline Yes & $13(24.1)$ & 14 (13.7) & $38(26.6)$ & $170(12.0)$ & 0.482 & $>0.999$ & 0.044 \\
\hline No & $41(75.9)$ & $88(86.3)$ & $105(73.4)$ & $1,252(88.0)$ & & & \\
\hline Age of OC (yr) & $49.2 \pm 11.2$ & $45.0 \pm 11.3$ & $46.3 \pm 16.6$ & $51.5 \pm 15.9$ & 0.615 & 0.800 & 0.754 \\
\hline \multicolumn{8}{|l|}{ Personal history of OC } \\
\hline Yes & $9(16.7)$ & $3(2.9)$ & $2(1.4)$ & $6(0.4)$ & 0.009 & $<0.001$ & $<0.001$ \\
\hline No & $43(79.6)$ & $99(97.1)$ & 141 (98.6) & $1,416(99.6)$ & & & \\
\hline Unknown & $1(1.9)$ & 0 & 0 & 0 & & & \\
\hline \multicolumn{8}{|l|}{ Family history of $O^{d}$ ) } \\
\hline Yes & $13(24.1)$ & $20(19.6)$ & $16(11.2)$ & $64(4.5)$ & $<0.001$ & $<0.001$ & 0.003 \\
\hline No & $39(72.2)$ & $82(80.4)$ & $127(88.8)$ & $1,358(95.5)$ & & & \\
\hline Unknown & $2(3.7)$ & 0 & 0 & 0 & & & \\
\hline No. of relatives with OC & $0.57 \pm 1.72$ & $0.20 \pm 0.40$ & $0.11 \pm 0.32$ & $0.05 \pm 0.21$ & 0.351 & 0.166 & 0.084 \\
\hline \multicolumn{8}{|l|}{ No. of relatives with $\mathrm{OC}$} \\
\hline 0 & $41(75.9)$ & $82(80.4)$ & $127(88.8)$ & $1,358(95.5)$ & $<0.001$ & $<0.001$ & $<0.001$ \\
\hline 1 & $11(20.4)$ & $17(16.7)$ & $16(11.2)$ & $63(4.4)$ & & & \\
\hline$\geq 2$ & $2(3.7)$ & $3(2.9)$ & 0 & $1(0.1)$ & & & \\
\hline Closet degree of relatives with $\mathrm{OC}$ & & NA & NA & NA & & & \\
\hline First-degree & $12(22.2)$ & $12(11.8)$ & $8(5.6)$ & $38(2.7)$ & 0.290 & 0.002 & $<0.001$ \\
\hline Second-degree & $3(5.6)$ & $7(6.9)$ & $7(4.9)$ & $17(1.2)$ & $>0.999$ & $>0.999$ & 0.084 \\
\hline \multicolumn{8}{|l|}{ ER status } \\
\hline Negative & $42(77.8)$ & $81(79.4)$ & $30(21.0)$ & $456(32.1)$ & 0.420 & $<0.001$ & $<0.001$ \\
\hline Positive & $8(14.8)$ & 14 (13.7) & $107(74.8)$ & $876(61.6)$ & & & \\
\hline Unknown & $4(7.4)$ & $7(6.9)$ & $6(4.2)$ & $90(6.3)$ & & & \\
\hline \multicolumn{8}{|l|}{ PR status } \\
\hline Negative & 45 (83.3) & 75 (73.5) & $51(35.7)$ & $487(34.2)$ & 0.035 & $<0.001$ & $<0.001$ \\
\hline Positive & $5(9.3)$ & 20 (19.6) & 85 (59.4) & $842(59.2)$ & & & \\
\hline Unknown & $4(7.4)$ & $7(6.9)$ & $7(4.9)$ & $93(6.5)$ & & & \\
\hline
\end{tabular}

(Continued to the next page) 
Table 2. Continued

\begin{tabular}{|c|c|c|c|c|c|c|c|}
\hline & \multirow{2}{*}{ L1780P } & \multicolumn{3}{|c|}{ KOHBRA study } & \multirow{2}{*}{ p-value ${ }^{a}$} & \multirow{2}{*}{ p-value ${ }^{\text {b) }}$} & \multirow{2}{*}{ p-value ${ }^{c}$} \\
\hline & & BRCA1 & BRCA2 & Non-BRCA1/2 & & & \\
\hline \multicolumn{8}{|l|}{ HER2 status } \\
\hline Negative & 49 (90.7) & $75(73.5)$ & $89(62.2)$ & $823(57.9)$ & 0.002 & $<0.001$ & $<0.001$ \\
\hline Overexpression & $2(3.7)$ & $7(6.9)$ & $14(9.8)$ & $253(17.8)$ & & & \\
\hline Equivocal & 0 & $8(7.8)$ & $29(20.3)$ & $208(14.6)$ & & & \\
\hline Unknown & $3(5.6)$ & 12 (11.8) & $11(7.7)$ & $138(9.7)$ & & & \\
\hline Male breast cancer & 1 & NA & NA & NA & NA & NA & NA \\
\hline
\end{tabular}

Values are presented as mean \pm standard deviation or number $(\%)$. HBOC, hereditary breast and ovarian cancer; L1780P, BRCA1 c.5339T>C (p.Leu1780Pro); KOHBRA, Korean Hereditary Breast Cancer; BC, breast cancer; OC, ovarian cancer; NA, not available; ER, estrogen receptor; PR, progesterone receptor; HER2, human epidermal growth factor-2. ${ }^{\text {a) }} \mathrm{p}$-value for L1780P vs. $B R C A 1,{ }^{b}$ p-value for L1780P vs. $B R C A 2,{ }^{c}$ p-value for L1780P vs. non-BRCA1/2, d) Seven patients had a family history of breast and ovarian cancer.

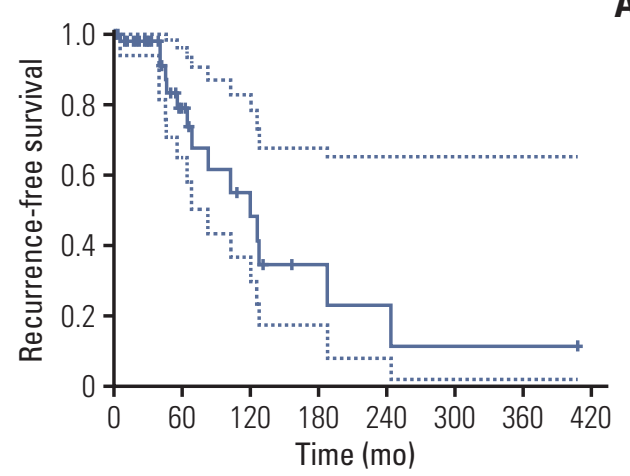

A

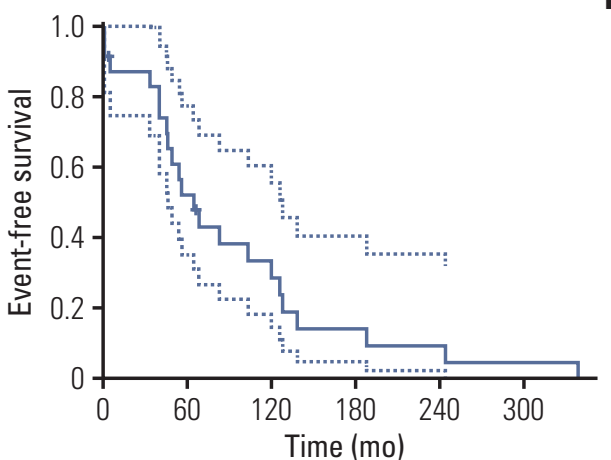

Fig. 2. Recurrence-free survival (A) and event-free survival (B) curves of breast cancer patients with BRCA1 c.5339T>C (p.Leu1780Pro).

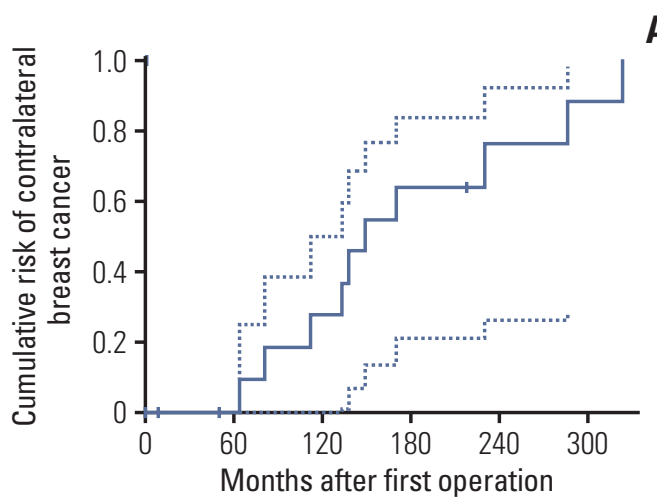

A

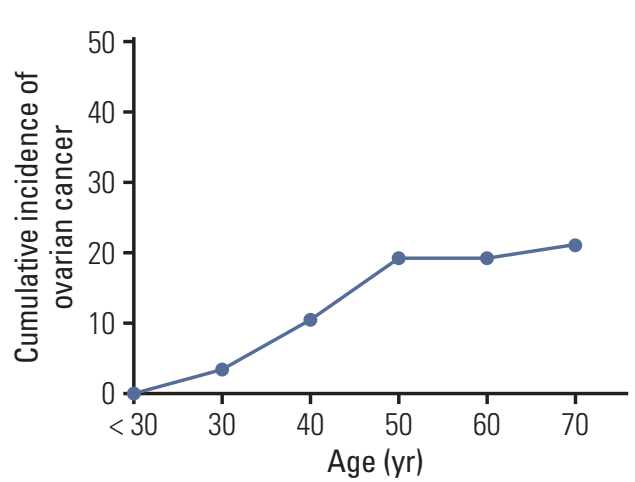

Fig. 3. Cumulative contralateral breast cancer (A) and cumulative ovarian cancer (B) incidence in patients with BRCA1 c.5339T>C (p.Leu1780Pro). 
Table 3. Previous studies reporting frequency of the BRCA1 c.5339T $>C$ (p.L1780P) variant

\begin{tabular}{|c|c|c|c|c|c|}
\hline $\begin{array}{l}\text { No. of L1780P } \\
\text { variants }\end{array}$ & $\begin{array}{l}\text { Total No. of } \\
\text { breast cancers }\end{array}$ & $\begin{array}{c}\text { Total No. of } \\
\text { ovarian cancers }\end{array}$ & $\begin{array}{c}\text { Proportion of } \\
B R C A 1 / 2 \text { mutation }\end{array}$ & $\begin{array}{l}\text { Proportion of } \\
B R C A 1 \text { mutation }\end{array}$ & Reference \\
\hline 4 & $4 / 328$ & NA & $4 / 49$ (10.3) & $4 / 21(19.0)$ & $\mathrm{NCC}$ \\
\hline 16 & $12 / 1,223^{a)}$ & $6 / 174(3.2)^{b)}$ & $16 / 244(6.6)$ & $16 / 139(11.5)$ & SMC \\
\hline 11 & $10 / 596^{c)}$ & $\left.3 / 124(2.4)^{c}\right)$ & $11 / 144(7.6)$ & $11 / 69$ (15.9) & YCC \\
\hline 2 & NA & $2 / 138(2.2)$ & $2 / 33(6.1)$ & $2 / 26(7.7)$ & CHA \\
\hline 64 & $54^{\text {d) }}$ & $14^{\mathrm{d})}$ & $64 / 458(12.8)$ & NA & Current study \\
\hline
\end{tabular}

Values are presented as number (\%). NA, not available; NCC, National Cancer Center; SMC, Samsung Medical Center; YCC, Yonsei Cancer Center. ${ }^{a}$ One patient was male breast cancer, $\left.{ }^{b}\right)$ Two patients had breast cancer and ovarian cancer, ${ }^{c}$ Three patients had breast cancer and ovarian cancer, ${ }^{\mathrm{d}}$ Nine patients had breast and ovarian cancer.

ents with L1780P variant, with the prevalence of the L1780P variant of $B C$ and OC being 26 of 2,147 (1.2\%) and 11 of 436 $(2.5 \%)$ and the proportions of the L1780P variant of BRCA1/2 and BRCA1 being 33 of $470(7.0 \%)$ and 255 (12.9\%), respectively [4-6,17]. In this study, 64 of 458 patients with a BRCA1/2 mutation $(12.8 \%)$ showed the L1780P variant. This suggests that L1780P is a common mutation in Korean patients with HBOC syndrome. In this study, among the seven patients (13.5\%) with family members with L1780P, the FHx of six patients $(11.1 \%)$ showed co-segregation patterns of $\mathrm{BC}$ and / or OC. The L1780P variant has been introduced as a likely pathogenic variant in recent years; however, segregation data from family members and haplotype analysis are not available, and such investigations are necessary to confirm whether L1780P is a founder mutation.

There are several reasons why a frequent and likely pathogenic variant (L1780P) had been classified as a VUS. One reason for its classification as a VUS may be the rare prevalence in Western countries. There was only one carrier who was of Asian ethnicity reported in the BIC database (http:// research.nhgri.nih.gov/bic/). Since the KOHBRA study was started in 2007, the number of patients undergoing BRCA1/2 genetic testing has increased rapidly due to coverage of $B R C A 1 / 2$ genetic testing by the National Health Insurance system of the South Korean government after May 2012 and the onset of the "Angelina Jolie effect" in May 2013 [11,18,19]. However, reclassification of VUSs in the Korean population is still not adequately performed due to limited data compared with Western public databases such as BIC or ClinVar (http://www.ncbi.nlm.nih.gov/clinvar/). VUSs continue to be uncovered as BRCA1/2 pathogenic variants, especially in developing countries. Of note, Korean clinicians asked Myrid about the possibility of L1780P as a pathogenic variant and categorized L1780P as a VUS according to previous functional studies $[20,21]$. Several years later, they amended that L1780P has been reclassified to a suspected deleterious mutation based on a recent functional study and clinical report
[4-6]. Even with many efforts to reduce VUSs, there is still a possibility that more pathogenic variants are classified as VUSs in the Korean population [22,23]. Thus, we should collect more data using nationwide or global databases to reduce the rates of VUS designation.

Rebbeck et al. [24] reported that $B C$ and $O C$ risks varied by type and location of $B R C A 1 / 2$ mutation, and that risk assessment and cancer prevention decision making for carriers should be approached based on the location of $B R C A 1 / 2$ mutation. The author demonstrated three breast cancer cluster regions (BCCRs) (c.179 to c.505, c.4328 to c.4945, and c.5261 to c.5563) and one ovarian cancer cluster region in BRCA1 mutation. Interestingly, L1780P is located in the BCCR but showed more likely to have OC compare to data of $\mathrm{KOH}$ BRA. Recently, Park et al. [25] demonstrated that patients with $\mathrm{L} 1780 \mathrm{P}$ showed a relative risk of BC similar to that of carriers with other known deleterious mutations located in the BRCT domains of BRCA1. In addition, age at diagnosis of BC in patients with L1780P (median, 38.4 years; 95\% confidence interval [CI], 33.9 to 42.9 ) was significantly earlier than that of carriers with mutations outside of the putative functional domain regions (median, 51.0 years; 95\% CI, 45.0 to 57.0 years; $p=0.017$ ). In this study, the mean age at diagnosis of BC in patients with L1780P showed no significant difference compared with that of patients with BRCA1 mutation in KOHBRA. Further investigations are needed to validate the location of BRCA1/2 mutation and the risk of cancer prevalence in Korea as well as the other parts of the world, especially in northeastern Asian countries.

There are some limitations in the present study, including its retrospective design and loss of data collection. However, a prospective cohort study on this topic may be nearly impossible and is not a suitable design for research on rare mutations in a specific population. Furthermore, to the best of our knowledge, the current study presents the largest number of patients with the L1780P variants to date and demonstrates clear clinicopathologic evidence that the L1780P 
variant is a pathogenic variant of $B R C A 1$.

In conclusion, patients with L1780P variant showed similar clinicopathologic features to patients with $B R C A 1$ pathogenic mutation, so that L1780P variant in BRCA1 should be considered as pathogenic BRCA1 mutation. RRSO should be highly recommended for women with the L1780P variant.

\section{Electronic Supplementary Material}

Supplementary materials are available at Cancer Research and Treatment website (https://www.e-crt.org).

\section{Conflicts of Interest}

Conflict of interest relevant to this article was not reported.

\section{Acknowledgments}

Dankook University Hospital, National Cancer Center, Korea University Hospital, Kyungpook National University Hospital, Samsung Medical Center, Dr. Moon-Woo Seong, Dr. Kyung-Hun Lee, Dr, Koung-Jin Suh, Dr. Dong-Young Noh, Dr. Wonshik Han, Dr. Han-Byoel Lee at Seoul National University Hospital, Seoul National University Bundang Hospital, St. Mary's Hospital, Yonsei
University Severance Hospital, and we thank all investigators of KOHBRA study.

\section{Author Details}

${ }^{1}$ Department of Surgery, Yonsei University College of Medicine, Seoul, ${ }^{2}$ Department of Surgery, Samsung Comprehensive Cancer Center, Samsung Medical Center, Sungkyunkwan University School of Medicine, Seoul, ${ }^{3}$ Cancer Prevention Center, Yonsei Cancer Center, Seoul, ${ }^{4}$ Department of Internal Medicine, Seoul National University Hospital, Seoul, ${ }^{5}$ Cancer Research Institute, Seoul National University College of Medicine, Seoul, ${ }^{6}$ Center for Breast Cancer, National Cancer Center, Goyang, ${ }^{7}$ Department of Surgery, Seoul National University College of Medicine, Seoul, ${ }^{8}$ Breast Care Center, Seoul National University Bundang Hospital, Seongnam, ${ }^{9}$ Department of Surgery, Seoul St. Mary's Hospital, College of Medicine, The Catholic University of Korea, Seoul, ${ }^{10}$ Department of Surgery, Dankook University College of Medicine, Cheonan, ${ }^{11}$ Department of Surgery, School of Medicine, Kyungpook National University, Daegu, ${ }^{12}$ Division of Breast and Endocrine Surgery, Department of Surgery, Korea University Anam Hospital, Korea University College of Medicine, Seoul, ${ }^{13}$ Department of Surgery, Breast Care Center, Daerim St. Mary's Hospital, Seoul, Korea

\section{References}

1. Lee EH, Park SK, Park B, Kim SW, Lee MH, Ahn SH, et al. Effect of BRCA1/2 mutation on short-term and long-term breast cancer survival: a systematic review and meta-analysis. Breast Cancer Res Treat. 2010;122:11-25.

2. Antoniou A, Pharoah PD, Narod S, Risch HA, Eyfjord JE, Hopper JL, et al. Average risks of breast and ovarian cancer associated with BRCA1 or BRCA2 mutations detected in case Series unselected for family history: a combined analysis of 22 studies. Am J Hum Genet. 2003;72:1117-30.

3. Tavtigian SV, Greenblatt MS, Goldgar DE, Boffetta P; IARC Unclassified Genetic Variants Working Group. Assessing pathogenicity: overview of results from the IARC Unclassified Genetic Variants Working Group. Hum Mutat. 2008;29: 1261-4.

4. Ryu JM, Kang G, Nam SJ, Kim SW, Yu J, Lee SK, et al. Suggestion of BRCA1 c.5339T>C (p.L1780P) variant confer from 'unknown significance' to 'Likely pathogenic' based on clinical evidence in Korea. Breast. 2017;33:109-16.

5. Park JS, Nam EJ, Park HS, Han JW, Lee JY, Kim J, et al. Identification of a novel BRCA1 pathogenic mutation in Korean patients following reclassification of BRCA1 and BRCA2 variants according to the ACMG standards and guidelines using relevant ethnic controls. Cancer Res Treat. 2017;49:1012-21.

6. Yoon KA, Park B, Lee BI, Yang MJ, Kong SY, Lee ES. Clinically significant unclassified variants in BRCA1 and BRCA2 genes among Korean breast cancer patients. Cancer Res Treat. 2017;49:627-34.

7. Choi DH, Lee MH, Bale AE, Carter D, Haffty BG. Incidence of BRCA1 and BRCA2 mutations in young Korean breast cancer patients. J Clin Oncol. 2004;22:1638-45.

8. Jang JH, Lee JE, Kwon MJ, Ki CS, Kim JW, Nam SJ, et al. Spectra of BRCA1 and BRCA2 mutations in Korean patients with breast cancer: the importance of whole-gene sequencing. J Hum Genet. 2012;57:212-5.

9. Han SH, Lee KR, Lee DG, Kim BY, Lee KE, Chung WS. Mutation analysis of BRCA1 and BRCA2 from 793 Korean patients with sporadic breast cancer. Clin Genet. 2006;70:496-501.

10. Park KS, Cho EY, Nam SJ, Ki CS, Kim JW. Comparative analysis of BRCA1 and BRCA2 variants of uncertain significance in patients with breast cancer: a multifactorial probability-based model versus ACMG standards and guidelines for interpreting sequence variants. Genet Med. 2016;18:1250-7.

11. Han SA, Park SK, Ahn SH, Lee MH, Noh DY, Kim LS, et al. The Korean Hereditary Breast Cancer (KOHBRA) study: protocols and interim report. Clin Oncol (R Coll Radiol). 2011; 23:434-41.

12. Ossa CA, Torres D. Founder and recurrent mutations in BRCA1 and BRCA2 genes in Latin American countries: state 
of the art and literature review. Oncologist. 2016;21:832-9.

13. Apostolou P, Pertesi M, Aleporou-Marinou V, Dimitrakakis C, Papadimitriou C, Razis E, et al. Haplotype analysis reveals that the recurrent BRCA1 deletion of exons 23 and 24 is a Greek founder mutation. Clin Genet. 2017;91:482-7.

14. Rebbeck TR, Friebel TM, Friedman E, Hamann U, Huo D, Kwong A, et al. Mutational spectrum in a worldwide study of 29,700 families with BRCA1 or BRCA2 mutations. Hum Mutat. 2018;39:593-620.

15. Ferla R, Calo V, Cascio S, Rinaldi G, Badalamenti G, Carreca $\mathrm{I}$, et al. Founder mutations in BRCA1 and BRCA2 genes. Ann Oncol. 2007;18 Suppl 6:vi93-8.

16. Kauff ND, Perez-Segura P, Robson ME, Scheuer L, Siegel B, Schluger A, et al. Incidence of non-founder BRCA1 and BRCA2 mutations in high risk Ashkenazi breast and ovarian cancer families. J Med Genet. 2002;39:611-4.

17. Choi MC, Jang JH, Jung SG, Park H, Joo WD, Song SH, et al. Unclassified variants of BRCA1 and BRCA2 in Korean patients with ovarian cancer. Int J Gynecol Cancer. 2018;28:308-15.

18. Lee J, Kim S, Kang E, Park S, Kim Z, Lee MH, et al. Influence of the Angelina Jolie announcement and insurance reimbursement on practice patterns for hereditary breast cancer. J Breast Cancer. 2017;20:203-7.

19. Kang E, Kim SW. The Korean Hereditary Breast Cancer study: review and future perspectives. J Breast Cancer. 2013;16:245-
53.

20. Lee MS, Green R, Marsillac SM, Coquelle N, Williams RS, Yeung $\mathrm{T}$, et al. Comprehensive analysis of missense variations in the BRCT domain of BRCA1 by structural and functional assays. Cancer Res. 2010;70:4880-90.

21. Rowling PJ, Cook R, Itzhaki LS. Toward classification of BRCA1 missense variants using a biophysical approach. J Biol Chem. 2010;285:20080-7.

22. So MK, Jeong TD, Lim W, Moon BI, Paik NS, Kim SC, et al. Reinterpretation of BRCA1 and BRCA2 variants of uncertain significance in patients with hereditary breast/ovarian cancer using the ACMG/ AMP 2015 guidelines. Breast Cancer. 2019; 26:510-9.

23. Lee JS, Oh S, Park SK, Lee MH, Lee JW, Kim SW, et al. Reclassification of BRCA1 and BRCA2 variants of uncertain significance: a multifactorial analysis of multicentre prospective cohort. J Med Genet. 2018;55:794-802.

24. Rebbeck TR, Mitra N, Wan F, Sinilnikova OM, Healey S, McGuffog L, et al. Association of type and location of BRCA1 and BRCA2 mutations with risk of breast and ovarian cancer. JAMA. 2015;313:1347-61.

25. Park JS, Lee ST, Han JW, Kim TI, Nam EJ, Park HS. Difference in risk of breast and ovarian cancer according to putative functional domain regions in Korean BRCA1/2 mutation carriers. Clin Breast Cancer. 2018;18:362-73. 